\title{
PENATAAN SERTIFIKASI KOMPETENSI AWAK KAPAL PENANGKAP IKAN DI INDONESIA
}

\section{ARRANGEMENT OF CERTIFICATION COMPETENCE CREW OF FISHING VESSEL IN INDONESIA}

\author{
Muhammad Syarif Budiman ${ }^{1}$, Budi Hascaryo Iskandar², Deni Achmad Seboer ${ }^{3}$ \\ ${ }^{1,3}$ Stasiun Lapang Kelautan \\ ${ }^{2}$ Departemen Pemanfaatan Sumberdaya Perikanan, \\ Fakultas Perikanan dan Ilmu Kelautan, Institut Pertanian Bogor \\ Korespondensi: budimansyarif75@gmail.com, ryo@psp-ipb.org, denisoeboer@gmail.com
}

\begin{abstract}
Competence crew of fishing vessels is one of the main factors supporting the success of fishing operations. Mastery of crew competence evidenced by a certificate of competence gained through education and training as well as certification testing crew of the fishing vessel by the competent authority. Crew competency standards fishing vessels must conform to the size of the vessel (ship's length and gross tonnage) and area fishing operations. This study aims to assess the gap that occurs between the crew competency certificates fishing vessels with provisions of existing law in Indonesia as well as a contributing factor. Research has been done on the ship measuring more than 30 GT in Pelabuhanratu Nusantara Fishery Port and Fishing Port Ocean Nijam Zachman Muara Baru Jakarta. Primary data obtained from the evidence documents crew (BST, seaman books, Ankapin, Atkapin, SKK) who were on board. Secondary data were obtained from the Sijil Crew, SPB, vessel size (length and GT), the area of fishing operations as well as legislation on the manning of fishing vessels that apply in Indonesia. Data processing was performed using descriptive analysis with qualitative approach. The results showed the majority of the crew of the fishing vessel Indonesia does not have a certificate of competence in accordance with applicable regulations. This is caused by the publication dispensation SPB and certification test execution time constraints. The authorities should make clear deadline for publishing the dispensation of SPB and multiply the time and place of the certification test that is easily accessible by the crew.
\end{abstract}

Keyword: competence, crew, fishing vessels. fishing operation

\begin{abstract}
ABSTRAK
Kompetensi awak kapal penangkap ikan merupakan salah satu faktor utama penunjang keberhasilan operasi penangkapan ikan. Penguasaan kompetensi awak kapal dibuktikan dengan sertifikat kompetensi yang didapatkan melalui pendidikan dan latihan serta uji sertifikasi awak kapal penangkap ikan oleh badan berwenang. Standar kompetensi awak kapal penangkap ikan harus sesuai dengan ukuran kapal (panjang kapal dan gross tonage) dan wilayah operasi penangkapan. Penelitian ini bertujuan untuk mengkaji kesenjangan yang terjadi antara sertifikat kompetensi awak kapal penangkap ikan dengan ketentuan perundangan yang berlaku di Indonesia beserta faktor penyebabnya. Penelitian telah dilakukan pada kapal ukuran lebih dari 30 GT di Pelabuhan Perikanan Nusantara Pelabuhanratu dan Pelabuhan Perikanan Samudra Nizam Zachman Muara Baru Jakarta. Data primer diperoleh dari bukti dokumen awak kapal (BST, buku pelaut, Ankapin, Atkapin, SKK) yang berada diatas kapal. Data sekunder diperoleh dari Sijil Awak Kapal, SPB, ukuran kapal (panjang dan GT), wilayah operasi penangkapan serta peraturan perundangan tentang pengawakan kapal penangkap ikan yang berlaku di Indonesia. Pengolahan data dilakukan menggunakan metode analisis deskriptif dengan pendekatan kualitatif. Hasil penelitian menunjukkan mayoritas awak kapal penangkap ikan Indonesia belum memiliki sertifikat kompetensi sesuai peraturan yang berlaku. Hal ini disebabkan oleh dispensasi penerbitan SPB dan keterbatasan waktu pelaksanaan uji sertifikasi. Pihak berwenang harus tegas menentukan batas waktu dispensasi penerbitan SPB serta memperbanyak waktu dan tempat uji sertifikasi yang mudah diakses oleh awak kapal.
\end{abstract}

Kata kunci: awak kapal, kapal penangkap ikan, kompetensi. operasi penangkapan 


\section{PENDAHULUAN}

\section{Latar belakang}

Setiap kapal yang berlayar harus berada dalam kondisi laik laut sehingga menjamin keselamatan dan keamanan selama kapal berlayar. Kapal yang laik laut adalah keadaan kapal yang memenuhi persyaratan keamanan dan keselamatan kapal, pencegahan pencemaran lingkungan perairan dari kapal, pengawakan, peralatan navigasi dan peralatan keselamatan, garis muat, pemuatan, kesejahteraan awak kapal dan kesehatan penumpang, status hukum kapal, manajemen keselamatan dan pencegahan pencemaran perairan dari kapal, serta manajemen keamanan kapal untuk berlayar di perairan tertentu.

FAO (2000) dalam Suwarjo (2010) menyatakan bahwa kegiatan penangkapan ikan di laut merupakan pekerjaan yang paling berbahaya di dunia. Profesi pelaut memiliki karateristik "3D" yaitu dangerous (berbahaya), dirty (kotor) dan difficult (sulit). Tingkat kecelakaan kapal penangkap ikan di dunia rata-rata 80 orang setiap 100.000 awak kapal, hal ini meningkatkan perhatian badan dunia (IMO, FAO, ILO) terhadap peningkatan keselamatan tenaga kerja kapal penangkap ikan. Penyebab kecelakaan utama pada kapal penangkap ikan adalah rendahnya kesadaran awak kapal tentang penting keselamatan kerja pada kegiatan penangkapan ikan baik keselamatan awak kapal, kapal, muatan serta lingkungan perairannya.

Arsham Mazaheri et al. (2015) banyak kecelakaan kapal terjadi akibat kesalahan awak kapal dalam membaca situasi dalam bernavigasi sehingga mengakibatkan kesalahan dalam pengambilan keputusan. Kesalahan terjadi akibat lemahnya kompetensi, sehingga sangat diperlukan penyusunan peraturan yang mengatur kompetensi pengawakan kapal.

Menurut Gael Morel dan Christine Chauvin (2006), besaran gaji pekerja awak kapal penangkap ikan diberikan dengan sistem bagi hasil. Semakin banyak hasil tangkapan, maka gaji yang diterima akan semakin besar. Hal ini menyebabkan awak kapal penangkap ikan seringkali bekerja melewati batas standar keselamatan demi mendapatkan hasil tangkapan yang banyak. Sehingga diperlukan perubahan dalam sistem penggajian, agar awak kapal tetap bekerja sesuai dengan batas standar keamanan dan keselamatan.
Menurut Peraturan Pemerintah RI Nomor 51 Tahun 2002 tentang Perkapalan, awak kapal perikanan adalah orang yang bekerja di kapal perikanan (kapal penangkap ikan, kapal pendukung operasi penangkapan, kapal pengangkut hasil tangkapan, pembudidayaan ikan, pengolahan ikan, pelatihan/penelitian perikanan) dengan beban tugas sesuai yang tertera dalam buku sijil.

Menurut Undang-undang Perikanan Nomor 45 Tahun 2009, Kapal perikanan adalah kapal, perahu, atau alat apung lainnya yang digunakan untuk kegiatan penangkapan ikan, mendukung operasi penangkapan ikan, pembudidayaan ikan, pengangkutan ikan, pengolahan ikan, pelatihan perikanan dan penelitian/ eksplorasi perikanan.

Menurut Undang-undang RI Nomor 17 Tahun 2008 tentang Pelayaran, Setiap awak kapal berhak mendapatkan kesejahteraan (gaji, jam kerja, jam cuti asuransi, dll) yang dicantumkan di dalam Perjanjian Kerja Laut (PKL). Awak kapal harus memiliki PKL dan disijil sesuai dengan sertifikat kompetensi dan sertifikat keahliannya.

Menurut Peraturan Pemerintah RI Nomor 07 Tahun 2011 tentang Kepelautan. Dokumen pengawakan kapal terdiri dari perjanjian kerja laut, sijil awak kapal, buku pelaut, sertifikat kompetensi dan sertifikat keahlian yang sesuai dengan jabatan diatas kapal. Dokumen sertifikat kompetensi awak kapal harus selalu dibawa selama kapal melakukan operasi penangkapan dan dilampirkan bersama dokumen kapal lainnya pada saat mengajukan Surat Izin Berlayar dari syahbandar.

Menurut Kepmenhub No.9 Tahun 2005 tentang Pendidikan dan Latihan, Ujian serta Sertifikasi Pelaut Kapal Penangkap Ikan, sertifikat keahlian (Certificate of Proficiency/COP) awak kapal perikanan terdiri dari Ahli Nautika Kapal Penangkap Ikan (ANKAPIN) untuk perwira dek dan Ahli Teknika Kapal Penangkap Ikan Tingkat (ATKAPIN) untuk perwira mesin. Standar uji mutu sertifikat tersebut mengacu pada peraturan international Standar Training of Certificate Watchkeeping-Fisheries (STCW-F) 1995 dari International Maritim Organozation (IMO).

Kewenangan pengawakan kapal penangkap ikan didasarkan pada tiga faktor utama yaitu Gross Tonage (GT) kapal, panjang kapal dan wilayah operasi pelayaran. Berdasarkan GT-nya, pengawakan kapal penangkap ikan dikelompokan menjadi 3 
yaitu :

1. Kapal 30 - 60 GT, COP Nahkoda Ankapin III, KKM Atkapin III.

2. Kapal 60 - 88 GT, COP Nahkoda Ankapin II, KKM Atkapin II.

3. Kapal > 88 GT, COP Nahkoda Ankapin I, KKM Atkapin I.

Berdasarkan ukuran panjang kapalnya, kewenangan pengawakan kapal penangkap ikan dikelompokan menjadi 3 yaitu :

1. Kapal panjang $<12 \mathrm{M}$, COP Nahkoda Ankapin III, KKM Atkapin III.

2. Kapal panjang $12-24 \mathrm{M}$, COP Nahkoda Ankapin II, KKM Atkapin II.

3. Kapal panjang $>24 \mathrm{M}$, COP Nahkoda Ankapin I, KKM Atkapin I.

Berdasarkan wilayah operasinya, kewenangan pengawakan kapal penangkap ikan dikelompokkan menjadi 3 yaitu :

1. Wilayah operasi perairan $<60$ Mil dan tidak termasuk ZEE Indonesia, COP Nahkoda Ankapin III, KKM Atkapin III.

2. Wilayah operasi $>60$ mil dan tidak termasuk ZEE Indonesia, COP Nahkoda Ankapin II, KKM Atkapin II.

3. Wilayah operasi ZEE Indonesia, COP Nahkoda Ankapin I, KKM Atkapin I.

Sertifikat keterampilan (Certificate of Competency/COC) awak kapal penangkap ikan terdiri dari : Basic Safety Training for all fishing vessel personal (BST-F), Advance Fire Figthing (AFF), Medical Emergency First Aid (MEFA), Medical Care on Board (MC), Radar Simulator, General Maritim Distress and Safety System (GMDSS, Survival Craft and Rescue Boat (SCRB), Shif Security Officer (SSO), Electronic Chart Display and Information System (ECDIS).

Menurut Peraturan Menteri dan Kelautan Perikanan RI Nomor : 08/PERMENKP/ 2012 tentang Kepelabuhan Perikanan, setiap kapal ikan yang akan berlayar wajib mendapatkan Surat Persetujuan Berlayar dari Syahbandar Perikanan.

Menurut Peraturan Menteri Kelautan dan Perikanan RI Nomor : 3/PERMENKP/2013 Kesyahbandaran di Pelabuhan Perikanan, salah satu syarat penerbitan SPB adalah sertifikat kelayakan pengawakan nakhoda dan Anak Buah Kapal (ABK). Kelengkapan dokumen pengawakan kapal terdiri dari sijil awak kapal, buku pelaut, COC dan COP. Dokumen sertifikat kompetensi awak kapal tersebut harus berada diatas kapal selama kapal beroperasi dan wajib dilampirkan pada saat kapal mengajukan SPB di syahbandar perikanan. Saat ini banyak awak kapal penangkap ikan
Indonesia yang tidak memiliki sertifikat kompetensi yang sesuai dengan peraturan perundangan yang berlaku. Penelitian ini bertujuan untuk mengkaji kesenjangan yang terjadi antara sertifikat kompetensi awak kapal penangkap ikan dengan ketentuan perundangan yang berlaku di Indonesia.

\section{METODE PENELITIAN}

Penelitian ini menggunakan metode survei dengan dianalisis secara deskriptif dengan pendekatan kualitatif. Permasalahan utama dalam penelitian ini adalah awak kapal penangkap ikan Indonesia banyak yang tidak memiliki sertifikat kompetensi sesuai ketentuan perundangan yang berlaku. Hal ini merupakan salah satu penyebab terjadi Ilegal, Unreported, Unregulated (IUU) fishing di Indonesia.

Penelitian lapang dilakukan pada bulan Oktober 2015-Januari 2016 dilaksanakan di PPN Palabuhanratu dan PPS Muara Baru Jakarta. Target penelitian adalah kapalkapal penangkap ikan dengan ukuran $>30$ GT dengan jumlah sample 100 kapal (25 kapal di PPN Palabuhanratu, 75 kapal di PPS Muara Baru Jakarta).

Pengambilan data dilakukan menggunakan metode survei lapangan dengan wawancara dan kuesioner. Data primer diperoleh dari bukti dokumen awak kapal (BST), buku pelaut, Ankapin, Atkapin, Surat Kecakapan Khusus/SKK) yang berada diatas kapal. Data sekunder diperoleh dari Sijil Awak Kapal, SPB, ukuran kapal (panjang dan GT), wilayah operasi penangkapan serta peraturan perundangan tentang pengawakan kapal penangkap ikan yang berlaku di Indonesia.

\section{HASIL DAN PEMBAHASAN}

Dalam kegiatan penelitian ini, awak kapal dikelompokkan menjadi dua yaitu perwira (nakhoda, mualim, Kepala Kamar Mesin/KKM, masinis) dan non perwira (bosman, ABK). Setiap awak kapal wajib memiliki sertifikat BST dan buku pelaut. Awak kapal dengan jabatan perwira dek wajib memiliki sertifikat Ankapin dan sertifikat Atkapin untuk perwira mesin. Tingkatan sertifikat Ankapin dan Atkapin seorang perwira harus sesuai dengan klasifikasi kapal berdasarkan ukuran panjang kapal, GT dan wilayah operasi.

Pimpinan tertinggi diatas kapal adalah nakhoda. Saputra et al. (2013) menyatakan bahwa seorang nakhoda sepenuhnya 
bertanggung jawab untuk memperlengkapi kapalnya dengan sempurna, mengawaki kapalnya secara layak sesuai prosedur, membuat kapalnya layak laut, bertanggung jawab atas keselamatan pelayaran, bertanggung jawab atas para pelayar yang ada diatas kapal, dan memenuhi perintah pengusaha kapal selama tidak menyimpang dari peraturan perundangan yang berlaku.

Gambar 1 menunjukkan sebaran pelabuhan pangkalan berdasarkan data didalam Surat Izin Usaha Penangkapan (SIUP) dan Surat Izin Penangkapan Ikan (SIPI) dari 100 kapal sample. Masing-masing kapal memiliki 1-4 pelabuhan pangkalan. Total ada 16 pelabuhan perikanan yang menjadi pangkalan tersebar mulai pelabuhan Sabang (Indonesia bagian barat) sampai Pelabuhan Ambon (Indonesia bagian timur) dengan 4 lokasi pelabuhan yang paling dominan yaitu PPS Jakarta, PPS Benoa, PPS Cilacap dan PPN Pelabuhanratu. Data ini menunjukkan bahwa dengan kondisi pengawakan kapal seperti saat ini, syahbandar dari pelabuhanpelabuhan tersebut masih memberikan izin operasi kepada kapal-kapal tersebut dengan menerbitkan SPB.

Gambar 2 menunjukkan 48\% kapal berukuran 30-60 GT. Menurut peraturan nakhoda wajib memiliki sertifikat Ankapin III, hanya $15 \%$ yang memiliki sertifikat Ankapin III. Ada 16\% kapal berukuran 6080 GT. Menurut peraturan nakhoda wajib memiliki sertifikat Ankapin II, tidak ada satupun nakhoda yang memiliki sertifikat Ankapin II. Ada 36\% kapal ukuran > 88 GT. Menurut peraturan nakhoda harus memiliki sertifikat Ankapin I, tidak satu pun ditemukan nakhoda yang memiliki sertifikat Ankapin I.

Gambar 3 menunjukkan 2\% kapal beroperasi di seluruh Alur Pelayaran Indonesia (API) kecuali ZEEI. Menurut peraturan nakhoda wajib memiliki sertifikat Ankapin II, tidak ada satu orangpun nakhoda yang memiliki sertifikat Ankapin II. Ada 98\% kapal beroperasi di ZEEI. Menurut peraturan nakhoda wajib memiliki sertifikat Ankapin I, tidak ditemukan nakhoda yang memiliki sertifkat Ankapin I.

Gambar 4 menunjukkan 74\% kapal panjang 12-24 meter. Menurut peraturan nakhoda wajib memiliki sertifikat Ankapin II, tidak ditemukan nakhoda yang memiliki sertifikat Ankapin II. Ada 26\% kapal panjang $>24$ meter. Menurut peraturan nakhoda wajib memiliki sertifikat Ankapin I, tidak ditemukan nakhoda yang memiliki sertifikat Ankapin I.
Gambar 5 menunjukkan bahwa berdasarkan tahun penerbitan sertifikat, ditemukan sertifkat SKK yang terbit setelah Tahun 2005. Dalam Peraturan Menteri Perhubungan No 9 Tahun 2005 menyatakan bahwa sertifikat yang diakui untuk perwira kapal ikan adalah Ankapin dan Atkapin.

Berdasarkan dokumen Sertifikat Kelaikan dan Pengawakan Kapal Penangkap Ikan dan Sijil Awak Kapal, setiap kapal terdiri mulai 12 sampai 16 orang awak kapal terdiri dari nakhoda, wakil nakhoda, KKM, wakil KKM, Bosman dan ABK. Diperkirakan dari 1400-an awak kapal tersebut tidak memiliki kualifikasi sertifikat kompetensi sesuai ketentuan perundanganyang berlaku sehingga menjadi salah satu penyebab terjadi IUU fishing di Indonesia.

Data hasil penelitian menunjukkan bahwa kondisi awak kapal penangkap ikan saat ini belum memenuhi persyaratan pengawakan yang sesuai dengan aturan Peraturan Menteri Perhubungan Nomor : KM 9 tahun 2005 tentang Pendidikan dan Latihan, Ujian serta Sertifikasi Pelaut Kapal Penangkap Ikan. Hal ini disebabkan oleh beberapa faktor penyebab, antara lain : dispensasi penerbitan SPB, keterbatasan waktu pelaksanaan uji sertifikasi, serta lama waktu dan biaya uji sertifikasi. Sudah 11 tahun peraturan ini ditetapkan, tetapi belum bisa di implementasikan dengan baik. Diperlukan langkah tegas dari pihak berwenang untuk percepatan peningkatan kompetensi awak kapal penangkapn ikan baik melalui program pendidikan dan latihan formal maupun informal yang mudah diakses di seluruh wilayah Indonesia.

Indriastiwi et al. (2011) menyatakan bahwa pemerintah harus mengambil langkah tegas dalam pemenuhan kebutuhan kompetensi sumberdaya manusia sesuai dengan kualifkasi yang dibutuhkan baik melalui diklat formal maupun informal. Wahyu P. Anggrahini (2010), menyatakan bahwa perusahaan pelayaran hendaknya menyediakan sumberdaya manusia (SDM) yang kompeten dengan keahlian dan keterampilan yang sesuai. Peningkatan kemampian SDM dapat dilakukan melalui diklat formal maupun informal.

Muhamad Ainul Huda et al. (2012) menyatakan bahwa solusi dalam upaya mencapai optimalisasi penerapan regulasi nasional terkait keselamatan kapal penangkap ikan yaitu kesesuaian persyaratan dengan aspek pertimbangan teknis kemudian ketegasan aturan dengan pertimbangan aspek hukum serta 
kesungguhan lembaga terkait dalam

menegakkan aturan yang telah dibuat.

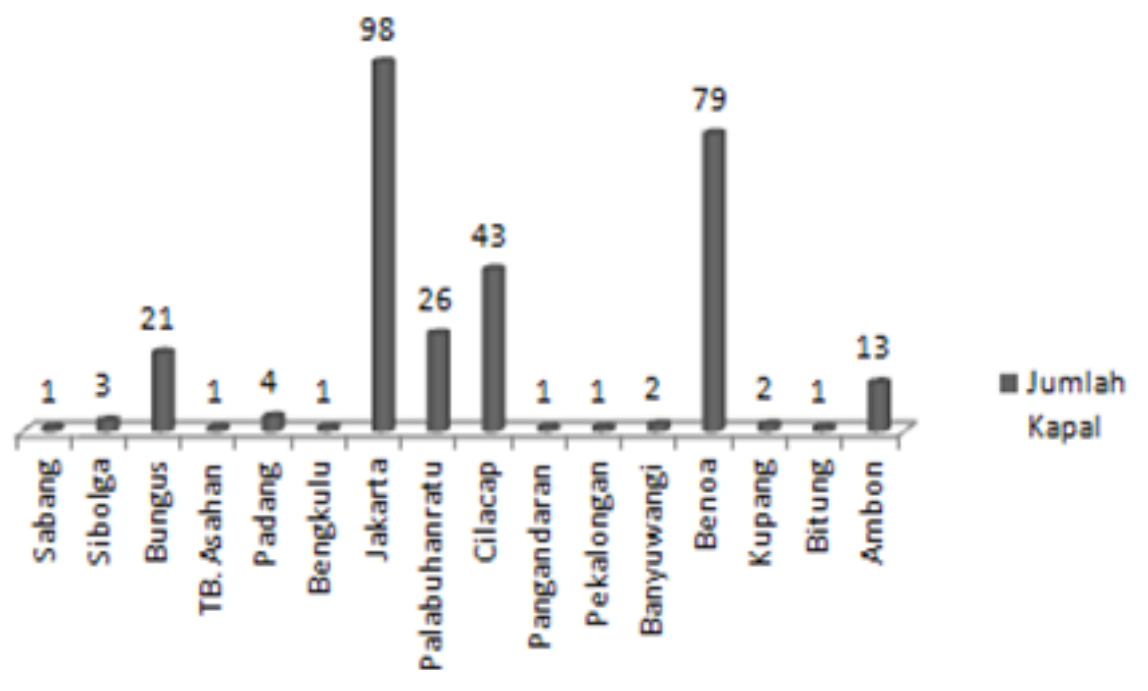

Gambar1. Pelabuhan pangkalan responden kapal

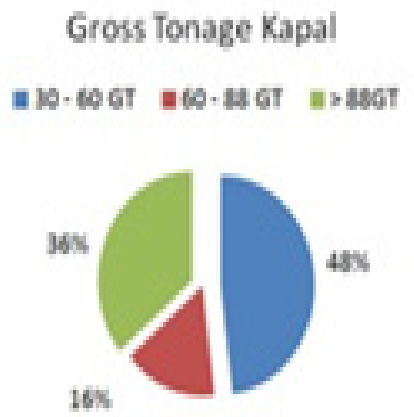

Kapal 30-60 GT

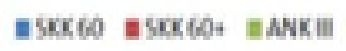

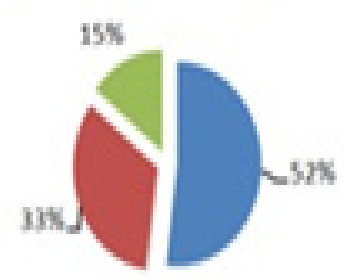

Kapal 60 - 83 GT

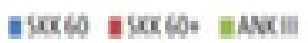

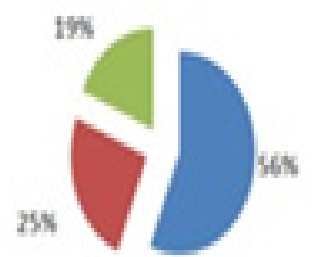

Gopal>B日

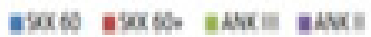

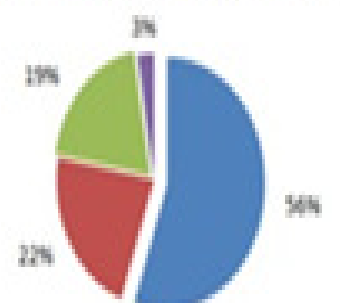

Gambar 2. Ukuran kapal berdasarkan GT 

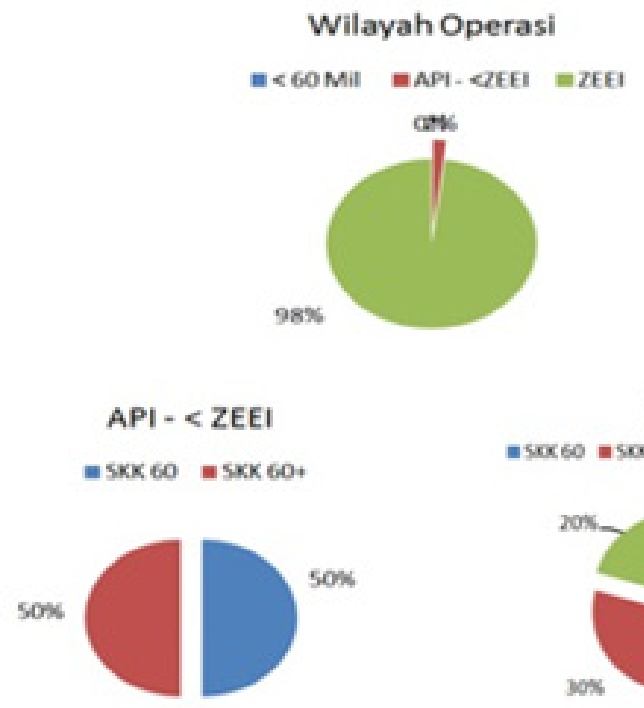

ZEEI

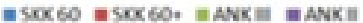

Gambar 3. Kapal berdasarkan wilayah operasi

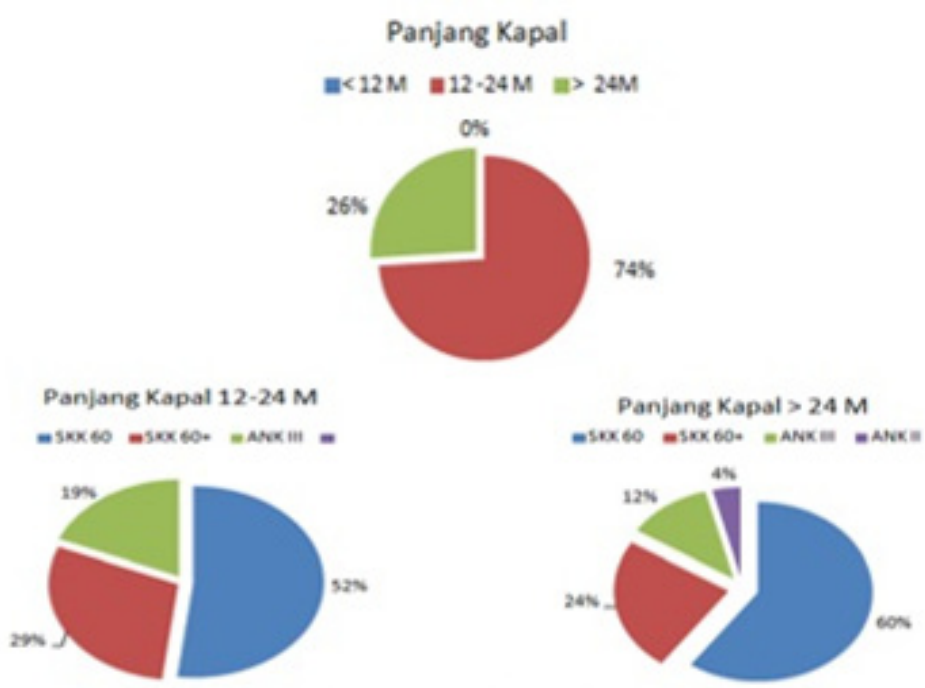

Gambar 4. Kapal berdasarkan panjang

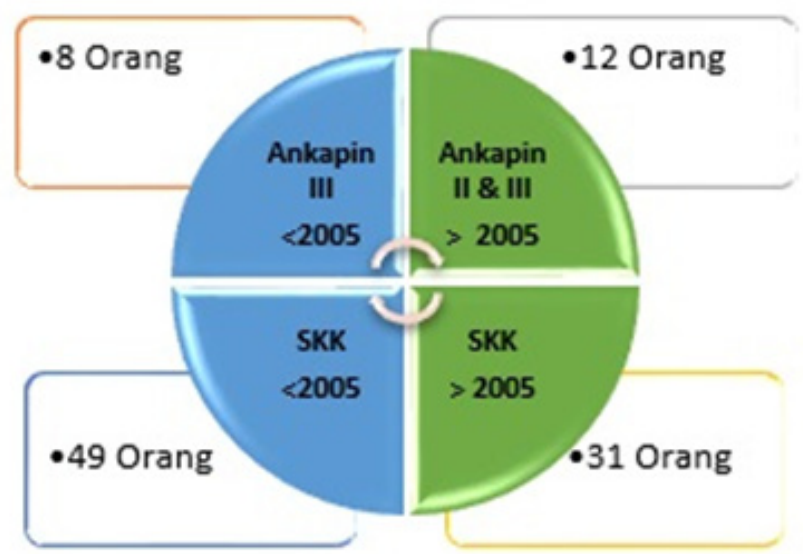

Gambar 5. Tahun penerbitan COP 


\section{KESIMPULAN DAN SARAN}

\section{Kesimpulan}

Sertifikat kompetensi awak kapal penangkap ikan Indonesia saat ini tidak memiliki kualifikasi sertifikat kompetensi sesuai ketentuan perudangan yang berlaku ( $>90 \%$ ) sehingga menjadi salah satu pemicu terjadi IUU fishing di Indonesia. Kesenjangan terjadi akibat dispensasi penerbitan SPB oleh syahbandar, keterbatasan waktu pelaksanaan uji sertifikasi, serta lama waktu dan biaya uji sertifikasi.

\section{Saran}

Pemerintah atau lembaga terkait harus segera memberikan ketegasan mengenai batas waktu dispensasi SPB, agar perusahaan perikanan dan awak kapal segera mengikuti diklat uji sertifikasi sesuai ketentuan. Pemerintah menambah frekuensi diklat uji sertifikasi dan menyiapkan tempat yang mudah di akses oleh awak kapal. Perusahaan penangkapan ikan mengarahkan kepada awak kapalnya untuk mengikuti diklat uji sertifikasi sehingga dapat menunjang kelancaran kegiatan operasi penangkapan.

\section{DAFTAR PUSTAKA}

Arsham M, Jakub M, Jari N, Pentti K. 2015. Usability of accident and incident reports for evidence-based risk modeling - A case study on ship grounding reports. Safety Science 76 (2015) $202-214$

Djojo S, John H, Indra J, Soen'an HP. 2010. Keselamatan kapal penangkap ikan, tinjauan dari aspek regulasi nasional dan international. Jurnal Teknologi Perikanan dan Kelautan. Vol 1 No 1. November 2010:1-13

Fitri I, Dienda R P. 2011. Kebutuhan kualifikasi sumberdaya manusia otoritas pelabuhan dalam rangka pelaksanaan tupoksi otoritas pelabuhan. J.Pen.Transla Vol.13 No.1 halaman 1-77 Maret 2011

Gael M dan Christine C. 2006. A sociotechnical approach of risk management applied to collisions involving Fishing Vessels. j.ssci.2006.01.002

Lazuardi S, Adwani, Mahfud. 2013. Tanggung jawab nakhoda kapal cepat angkutan penyebrangan terhadap kelaiklautan kapal dalam keselamatan dan keamanan pelayaran. Jurnal Ilmu Hukum Universitas Syiah Kuala. Vol.2 No. 2 November 2013.

Muhammad A H, Herry B, Indradi S. 2012. Implementasi regulasi nasional terkait keselamatan kapal penangkap ikan di PPN Pekalongan. Journal of Fisheries Resourches Utilization Management and Technology Volume 1, Nomor 1, Tahun 2012 Hlm 87 -96

Peraturan Pemerintah Republik Indonesia Nomor : 51 Tahun 2002 tentang Perkapalan

Peraturan Menteri Perhubungan Nomor : KM 9 tahun 2005 tentang Pendidikan dan latihan, ujian serta sertifikasi pelaut kapal penangkap ikan

Peraturan Pemerintah RI Nomor 07 Tahun 2011 tentang Kepelautan

Peraturan Menteri Kelautan dan Perikanan Nomor : 07/ PERMEN. KP/ 2011 tentang sistem standar mutu pendidikan dan pelatihan, ujian dan sertifikasi pelaut kapal penangkap ikan

Peraturan Menteri dan Kelautan Perikanan RI Nomor : 08/PERMEN-KP/ 2012 tentang kepelabuhan perikanan

Peraturan Menteri Kelautan dan Perikanan RI Nomor : 3/PERMEN-KP/2013 Kesyahbandaran di pelabuhan perikanan

Undang-undang RI Nomor 17 Tahun 2008 tentang pelayaran

Undang-undang Perikanan Nomor 45 Tahun 2009 tentang perikanan

Wahyu PA. 2010. Kajian penerapan manajemen keselamatan dan keamanan pengoperasian kapal 